\title{
Supervisi Pembelajaran Berbasis E-learning dalam Google Classroom pada Masa Pandemi Covid-19
}

\author{
Ahmad Tarmidzi Tahir \\ Universitas Islam Negeri Maulana Malik Ibrahim Malang \\ e-mail: taherplg@gmail.com
}

\begin{abstract}
Considering the current problem of the Covid-19 outbreak which has taken many lives so that all activities are temporarily based on WFH. One effort to be able to continue implementing learning in education is to use the Google Classroom application, so here the researchers formulated their focal points as follows: (1) How is the implementation of e-learning based learning in Google Classroom in Covid-19 Pandemic Situations, (2) What methods used in e-learning based learning in Google Classroom in Covid-19 Pandemic Situation, and (3) how to supervise e-learning based learning in Google Classroom in Covid-19 Pandemic Situation. The purpose of this study is: (1) analyzing how the implementation of e-learning based on Google Classroom in COVID-19 situations, (2) To describe the methods used in learning based on e-learning based on Google Classroom in COVID-19 situations, and (3) To describe the implementation of e-learning-based learning supervision in Google Classroom in Covid-19 Pandemic Situation. In this study, the researcher used descriptive qualitative, while the data collection techniques used interviews and documentation. The results of this study are: (1) In learning, an educator gives an assignment that is required to be written and then sent to the student through the Google Classroom application. This can be likened to sending messages via email, (2) Using the LMS (Learning Management System) method which is a software for documenting, reporting, and delivery in tutoring that is provided for students and educators, (3) Supervision of learning towards students can be done manually such as: if there are questions in the form of essays then the value is assessed manually not automatically.
\end{abstract}

Keywords. Learning supervision; Google Classroom

Abstrak. Mengingat permasalahan yang terjadi saat ini wabah Covid-19 yang telah banyak memakan korban jiwa sehingga menjadikan seluruh kegiatan untuk sementara berbasis WFH. Salah satu upaya untuk dapat tetap melaksanakan pembelajaran dalam pendidikan yaitu menggunakan aplikasi Google Classroom, maka disini peneliti merumuskan titik fokusnya sebagai berikut: (1) Bagaimanakah pelaksanaan pembelajaran berbasis e-learning dalam Google Classroom di Situasi Pandemi Covid-19, (2) Metode apakah yang digunakan dalam pembelajaran berbasis e-learning dalam Google Classroom di Situasi Pandemi Covid-19, dan (3) bagaimanakah pelaksanaan supervisi pembelajaran berbasis e-learning dalam Google Classroom di Situasi Pandemi Covid-19. Adapun tujuan penelitian ini ialah: (1) menganalisis bagaimana pelaksanaan pembelajaran berbasis e-learning Google Classroom di situasi covid-19, (2) Untuk mendeskripsikan metode yang digunakan dalam pembelajaran barbasis e-learning dalam Google Classroom disituasi covid-19, dan (3) Untuk mendeskripsikan pelaksaan supervisi pembelajaran berbasis e-learning dalam Google Classroom di Situasi Pandemi Covid-19. Dalam penelitian ini sang peneliti menggunakan deskriptif kualitatif, sedangkan dalam teknik pengumpulan datanya menggunakan wawancara dan dokumentasi. Hasil dari penelitian ini ialah: (1) Dalam pembelajarannya seorang pendidik memberikan tugas yang diwajibkan untuk ditulis kemudian dikirimkan 
kepeserta didik melalui aplikasi Google Classroom. Hal ini bisa disamakan seperti mengirim pesan lewat email, (2) Menggunakan metode LMS (Learning Management System) yang merupakan sebuah perangkat lunak bagi perdokumenan, pelaporan, dan penyampaian dalam bimbingan belajar yang disediakan untuk peserta didik dan pendidik, (3) Supervisi pembelajaran terhadap peserta didik dapat dilakukan secara manual seperti: jika terdapat soal berupa essay maka nilainya dinilai dengan cara manual tidak otomatis.

Kata Kunci. Supervisi pembelajaran; Google Classroom

Copyright (C) JMPI: Jurnal Manajemen Pendidikan Islam. All Right Reserved.

This is an open access article under the CC BY-NC-ND license

(http://creativecommons.org/licenses/by-nc-nd/4.0/).

\section{A. PENDAHULUAN}

Melihat dunia yang semakin canggih dan modern serta selalu mengeluarkan hasil pekembangannya yang terus menerus baik dari segi teknologi, ekonomi, sosial, dan pendidikan. Dimana semua ini selalu diusahakan untuk dapat berkembang seiring dengan zaman yang semakin maju ini. Beragam cara dilakukan demi terpenuhinya tujuan yang ingin dicapai oleh setiap Negara. Akan tetapi orang tidak dapat bisa berfikir inovatif dan kreatif untuk melakukan semua ini tanpa mempunyai bidang keilmuan di dalam dirinya. Maka, diperlukannyalah pendidikan yang dapat memberikan beragam pembelajaran sehingga seseorang dapat mengeluarkan opini yang dia punya untuk memajukan Negara.

Pendidikan sendiri merupakan pembelajaran ilmu pengetahuan, seni dalam keterampilan, dan sesuatu yang dibiasakan orang untuk ditunkan dari satu generasi kegenerasi berikutnya. Sedangkan pembelajaran menurut Sadiman, dkk, (1986:2) definisi dari kata belajar (learning) merupakan proses yang terjadi kepada setiap orang yang dilakukan di rumah, lembaga pendidikan sekolah, tempat kerja, tempat beribadah, dan di dalam lingkungan masyarakat. Heinich (1999:8) mengungkapkan bahwasannya belajar ialah kegiatan dalam menunmbuhkembangkan ilmu pengetahuan, seni, dan perilaku sebagai proses dalam berinteraksi seseorang dengan lingkungannya agar dalam proses belajar dapat dilihat maka melalui bagaimana seseorang tersebut dapat melakukan pemilihan, pengelolaan, penyampaian yang sesuai melalui sebuah interaksi tersebut. Proses dalam belajar pun terjadi terhadap semua orang yang mana telah dilakukan sejak masih bayi hingga ke liang lahat nantinya. Adapun bukti bawasannya seseorang tersebut telah melakukan proses belajar maka terjadinya perubahan dalam perilaku sikap di dalam diri seseorang.

Mengingat permasalahan yang terjadi saat ini menimpa seluruh masyarakat baik di negeri Indonesia maupun di luar negeri Indonesia yaitu wabah Covid-19 yang telah banyak memakan korban jiwa sehingga menjadikan seluruh kegiatan libur untuk sementara dan berbasis Work from Home (WFH) (Mungkasa, 2020). Termasuk program pendidikan pun dilakukan berbasis WFH. Salah satu untuk dapat tetap melaksanakan pendidikan dalam konteks WFH ialah dengan menggunakan e-learning yaitu pembelajaran dengan menggunakan teknologi internet dengan tujuan untuk meningkatkan proses belajar mengajar dalam lingkungan yang luas dan wawasan yang luas juga.

E-learning sendiri ialah penggunaan internet dalam proses pembelajaran untuk dapat mengirimkan berbagai bentuk solusi dengan tujuan terciptanya suatu 
peningkatan terhadap ilmu pengetahuan dan seni dalam keterampilan. Dalam setiap bentuk metode dari pembelajaran diharuskan untuk menyertakan rumusan dari penggolongan materi pelajaran, strategi dalam penyampaian materi, dan menyelenggarakan aktivitas kegiatan dengan merumuskan beberapa factor dari tujuan belajar, kendala dalam belajar, kiat-kiat peserta didik untuk mendapatkan suatu yang berbentuk efektif, efisien dan daya tarik dari pembelajaran (Miarso, 2004).

Dalam pembelajaran secara daring yang berbasisi e-learning di sini lebih mengandalkan program dari aplikasi Google Classroom sebagai bentuk berjalannya proses belajar mengajar dalam pembelajaran. Google Classroom sendiri ialah sebuah aplikasi yang digunakan dalam pembelajaran secara online. Selain itu juga dapat membantu untuk dapat menemukan jalan keluar dari berbagai macam permasalahan yang dihadapi dalam suatu penugasan tanpa melalui sebuah kertas. Pemanfaatan virtual menjadi solusi dalam pembelajaran di masa pandemic (Sauri dkk., 2020). Melalui aplikasi dari Google Classroom dinyatakan bahwasannya tujuan dari proses pembelajaran akan menjadi sangat mudah diwujudkan. Maka dari itu, dalam menggunakan aplikasi Google Classroom dalam realitanya dapat menjadikan pendidik lebih ringan dalam menggarap pembelajaran dan dalam mengalirkan suatu informasi dengan sesuai dan akurat kepada peserta didik (Hardiyana, 2015). Google Classroom dalam (ruangan kelas Google) merupakan sebuah rangkaian pembelajaran yang bisa ditunjukkan kepada seluruh ranah dari ruang lingkupnya Pendidikan yang artinya agar dapat menolong untuk memecahkan permasalahan yang sedang ditangani dalam menggarap penugasan tanpa memerlukan sebuah kertas (paperless) (Qomariyah dan Nursobah, 2019).

Adapun aplikasi ini dikenal sebagai bagian dari Google Apps for Education (GAFE) dari sejak tanggal 12 Agustus 2014. Dengan menggunakan aplikasi ini dalam penyelenggaraan program pembelajaran maka akan dapat dikerjakan secara mendalam. Hal ini dikarenakan pendidik atau peserta didik dapat mengumpulkan berbagai tugas, mendefinisikan tugas, dan mengoreksi tugas serta memberikan nilai tanpa adanya keterikatan dengan batasan yang dideadlinekan. Selain itu, imlementasi dari proses pembelajaran menggunakan Google Classroom akan dapat lebih meringankan pekerjaan para pendidik untuk melaksanakan pengoreksian dari terselenggaranya proses belajar mengajar dalam ruang kelas atau diluar ruangan.

Berdasarkan realita yang terjadi maka sang peneliti ingin meneliti: Bagaimanakah pelaksanaan pembelajaran berbasis e-learning dalam Google Classroom di Situasi Pandemi Covid-19 di SMP Negeri I Adimulyo Kebumen. Metode apakah yang digunakan dalam pembelajaran berbasis e-learning dalam Google Classroom di Situasi Pandemi Covid-19 di SMP Negeri I Adimulyo Kebumen, dan bagaimanakah pelaksanan supervisi pembelajaran berbasis e-learning dalam Google Classroom di situasi Pandemi Covid-19 di SMP Negeri I Adimulyo Kebumen.

Adapun tujuan penelitian ialah untuk menganalisis bagaimana pelaksanaan pembelajaran berbasis e-learning Google Classroom di situasi covid-19 di SMP Negeri I adimulyo kabumen. Untuk mendeskripsikan metode yang digunakan dalam pembelajaran barbasis e-learning dalam Google Classroom di situasi covid-19 di SMP Negeri I adimulyo kabumen, untuk mendeskripsikan pelaksaan supervisi pembelajaran berbasis e-learning dalam Google Classroom di Situasi Pandemi Covid-19 di SMP Negeri I Adimulyo Kebumen. 
Sedangkan manfaat penelitian ialah mengetahui pelaksanaan pembelajaran berbasis e-learning dalam Google Classroom di situasi covid-19 di SMP Negeri I adimulyo kabumen. Mengetahui metode yang digunakan pembelajaran berbasis e-learning dalam Google Classroom di situasi covid-19 di SMP Negeri I adimulyo kabumen, dan untuk mengetahui pelaksanaan supervisi pembelajaran berbasis e-learning dalam Google Classroom di Situasi Pandemi Covid-19 di SMP Negeri I Adimulyo Kebumen.

\section{B. METODE}

Dalam penelitian ini sang peneliti menggunakan deskriptif kualitatif. Mengapa peneliti menggunakan deskriptif kualitaif dikarenakan peneliti ingin melukiskan suatu realita dari sebuah kejadian (Sugiyono, 2006) yang nampak dalam pembelajaran Google Classroom. Penelitian deskripstif kualitatif ialah penelitian yang melukiskan objek dari penelitian yang berlandaskan dari sebuah kenyataan atau realitanya dengan apa adanya (Nawawi dan Martini, 1996: 73). Adapun teknik pengumpulan datanya melalui wawancara dan dokumentasi. Yang mana dalam wawancara dilakukan semi struktur dengan berbagai guru di SMP Negeri I Adimulyo Kebumen. Wawancara sendiri dapat dilakukan secara terstruuktur atau tidak dengan secara face to face atau melalui via telephone (Sugiono, 2006: 138-140). Sedangkan dokumentasi dilakukan dengan menyertakan hasil pembelajaran berupa foto screenshot dari hasil pembelajaran Google Classroom antara pendidik dan peserta didik. Dokumentasi merupakan pengumpulan data yang digunakan untuk menemukan sebuah data yang bersifat historis. Mengenai orang, kelompok, kejadian yang memberikan hubungan yang urgent dalam penelitian kualitatif (yusuf, 2014). Penelitian ini dilakukan pada semester genap 2020 tanggal 9 mei 2010 hari sabtu terhadap lembaga pendidikan sekolah SMP Negeri I adimulyo kebumen sebanyak 2 orang pendidik.

\section{HASIL DAN PEMBAHASAN}

\section{Pelaksanaan Pembelajaran Berbasis E-learning Dalam Google Classroom di Situasi} Pandemi Covid-19 di SMP Negeri I Adimulyo Kebumen

"Dalam pelaksaan pembelajaran menggunakan Google Classroom masih dirasa kurang efektif dan maksimal karena terbiasa menyampaikan materi dengan bertatap muka dan tidak menggunakan aplikasi seperti ini dan hal ini juga dirasa cukup baru bagi saya dalam menggunakannya sehingga membutuhkan penyesuaian" (Amirotun lutfiyah, 2020).

Hal diatas adalah merupakan tanggapan dari salah satu pendidik yang menggunakan aplikasi ini di SMPN I Adimulyo Kebumen dalam proses pembelajarannya. Dalam pelaksanaan pembelajaran menggunakan aplikasi Google Classroom ialah seluruh peserta didik diharuskan mengakses aplikasi Google Classroom dengan menggunakan google pribadi yang ada dilaptop atau smartphone mereka masing-masing. Melalui hal ini maka, dapat dimanfaatkan oleh pendidik, murid, dan wali murid saat melakukan proses belajar mengajar. Dalam pembelajarannya seorang pendidik memberikan tugas yang diwajibkan untuk ditulis kemudian dikirimkan kepeserta didik melalui aplikasi Google Classroom. Hal ini bisa disamakan seperti mengirim pesan lewat email. Adapun mengenai waktu pembelajaran bersifat fleksibel dan mengenai penugasan dapat diatur oleh pendidik sendiri jika menginginkan adanya deadline batas pengumpulan tugas atau tidak. Selain itu juga mengapa harus 
menggunakan aplikasi ini dikarenakan banyak keuntungan yang didapatkan seperti aplikasi ini gratis, tidak sulit dan mudah digunakan dan lainnya.

Hal ini senada dengan kelebihan yang terdapat pada aplikasi Google Classroom yang yang diungkapkan oleh Janzem dalam Iftakhar (2016: 13) yaitu ringan jika digunakan, dapat menghemat waktu, berbasis pada cloud, mempunyai sifat yang fleksibel yang disebut juga sebagai mengikuti sesuai situasi kapanpun dan dimanapun bisa digunakan atau elastis, dan tidak dipungut biaya atau berbayar.

Dalam pembelajaran menggunakan Google Classroom bahwa seorang pendidik memberikan tugas terhadap peserta didik juga telah dijelaskan oleh (Hardiyana, 2015) yang merupakan bagian dari tujuan Google Classroom yaitu: memberikan kemudahan untuk direalisasikan dan sehingga pendidik dalam mengatur pembelajaran dan pengimplementasian informasi secara akurat. Dengan ini maka pendidik dapat memberikan seputar informasi mata kuliah seperti pemberian tugas hinga mengumpukan tugas tersebut dalam aplikasi Google Classroom ini yaitu dengan mengupload, daftar nilai, informasi mengenai perkuliahan, pembagian kelompok kerja, serta upload bahan untuk mengajar.

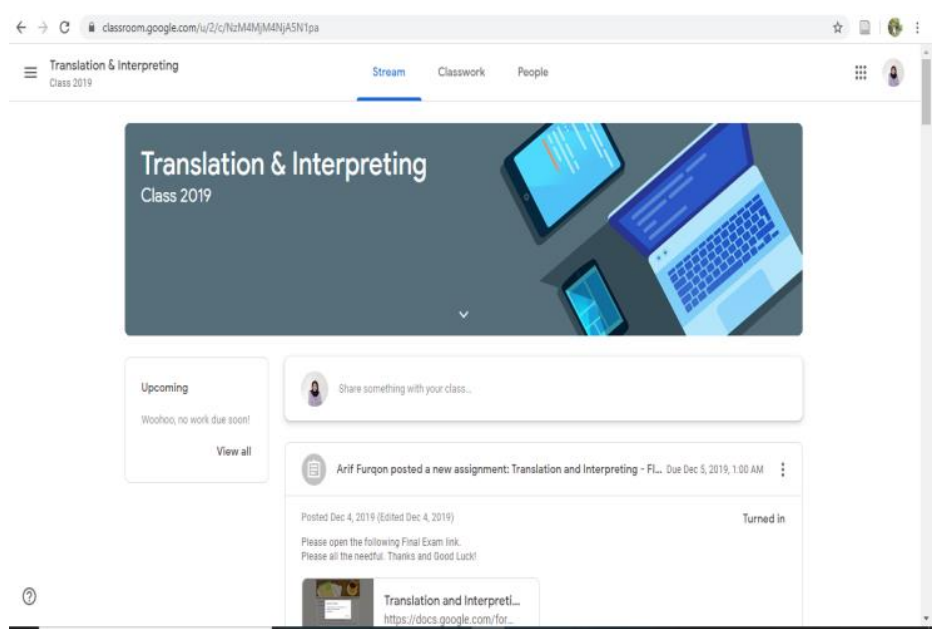

Metode yang digunakan dalam pembelajaran berbasis e-learning dalam Google Classroom di Situasi Pandemi Covid-19 di SMP Negeri I Adimulyo Kebumen

Dalam pembelajaran yang diberikan oleh para pendidik di SMPN I mengarah kepada metode LMS (Learning Management System) yang merupakan sebuah perangkat lunak bagi perdokumenan, pelaporan, dan penyampaian dalam bimbingan belajar yang disediakan untuk peserta didik dan pendidik. LMS sendiri dalam proses pembelajarannya menggunakan system computer, dan internet yang ditujukan untuk mengatur pembelajaran secara online, menyampaikan materi pembelajaran, memberikan laporan sebuah aktivitas, yang mana semua ini terhubung dan dapat diakses melalui internet. Selain itu, peserta didik dapat mengakses tugas, buku, dan materi. Mengapa digunakannya metode LMS dalam aplikasi Google Classroom hal ini dikarenakan LMS mempunyai banyak fitur sehingga dapat dikatakan memberi kemudahan para penggunanya seperti dalam dunia pembelajaran bagi pendidik dan peserta didik.

Hal ini senada dengan apa yang dikatakan (Ellis, 2009) yang mengatakan bahwa LMS merupakan perangkat lunak yang disediakan untuk kebutuhan administrasi, 
dokumentasi, laporan dari suatu acara atau aktivitas, KBM dan aktivitas yang mengarah kepada dunia internet atau online, e-learning dan beberapa mengenai materi Training. Hal ini juga sepaham dengan apa yang diungkapkan oleh Laster, 2005; Mullinix \& McCurry, 2003; Simpson \& Payne, 1999 dalam Gredler (2011) yaitu LMS merupaka program software yang terdapat beberapa macam fitur didalamnya yang diperlukan oleh pendidik dan peserta didik dalam proses pembelajaran agar dapat mengatur kelas dan saling bertukar pesan informasi dengan peserta didik lainnya. Selain itu dalam mengakses materi pembelajaran pun dapat terjadi dalam kisaran waktu yang telah ditetapkan.

\section{Supervisi Pembelajaran Berbasis E-learning Dalam Google Classroom di Situasi Pandemi Covid-19 di SMP Negeri I Adimulyo Kebumen}

Supervisi pembelajaran terhadap peserta didik dapat dilakukan secara manual seperti: jika terdapat soal berupa essay maka nilainya dinilai dengan cara manual tidak otomatis. Adapun system dari Google Classroom seperti kirim email yang mana pendidik mengirimkan materi berupa tugas sedangkan peserta didiknya berusaha untuk menjawabnya. Akan tetapi yang berbeda ialah hanya pada tampilan berandanya saja. Dalam aplikasi Google Classroom pendidik dalam mensupervisi peserta didik dapat dilakukan dengan memberikan materi pembinaan dan bimbingan (Amirotun Lutfiyah, 2020).

Mengenai pelaksanaan supervisi yang dilakukan pengawas terhadap para pendidik dalam supervisi pembelajaran juga sama dengan supervisi yang dilakukan pendidik terhadap peserta didiknya meliputi: memberikan pembinaan lebih terhadap pendidik walau hanya berkomunikasi jarak jauh tanpa bertatap muka, terjadinya pemantauan yang diberikan pengawas terhadap pendidik dalam proses $\mathrm{KBM}$, berbagai bimbingan terus diberikan terhadap pendidik guna menjadikan peserta didik yang terus berkemampuan. Hal ini tidak memandang waktu, yang mana pada saat ini terjadinya covid-19 maka, juga mengharuskan pengawas agar melakukan supervisi walaupun secara online.

Hal ini senada dengan apa yang diungkapkan dalam Kompasiana oleh Rudi Ahmad Suryadi bahwa hal penting dalam terjalannya supervisi ini ialah pengawas. Disini dia memiliki tugas berupa memastikan proses akademik dan manajerial yang terjadi dilmbaga pendidikan sekolah apakah telah memenuhi prosedur atau sesuai dengan ketetapan yang berlaku. Proses pembinaaan, pemantauan, dan pembimbingan terhadap suatu jasa layanan supervisi harus tetap mengikuti perkembangan walaupun keadaan yang berbeda seperti saat ini sedang terjadinya wabah covid-19 yang mengharuskan kita melakukan pekerjaan melalui aplikasi serba online. Seorang pengawas dituntut untuk bisa mengintegrasikan ketiga proses tersebut pada situasi saat ini. Sehingga apa yang menjadi tujuan yaitu control mutu sekolah akan selalu terus menerus berjalan.

\section{KESIMPULAN}

Disini dapat diketahui bahwasannya kesimpulan dari berbagai jenis penjelasan dapat dikategorikan sebagai berikut: Pelaksanaan pembelajaran berbasis e-learning dalam Google Classroom ialah seluruh peserta didik diharuskan mengakses aplikasi Google Classroom dengan menggunakan google pribadi yang ada dilaptop atau smartphone mereka masing-masing. Melalui ini maka, dapat dimanfaatkan oleh pendidik, murid, dan wali murid saat melakukan proses belajar mengajar. Dalam 
pembelajarannya seorang pendidik memberikan tugas yang diwajibkan untuk ditulis kemudian dikirimkan kepeserta didik melalui aplikasi Google Classroom. Hal ini bisa disamakan seperti mengirim pesan lewat email. Adapun mengenai waktu dapat diatur oleh pendidik sendiri jika menginginkan adanya deadline batas pengumpulan tugas atau tidak. Selain itu juga mengapa harus menggunakan aplikasi ini dikarenakan banyak keuntungan yang didapatkan seperti aplikasi ini gratis, tidak sulit dan mudah digunakan dan laiinya.

Dalam pembelajaran yang diberikan oleh para pendidik di SMPN I mengarah kepada metode LMS (Learning Management System) yang merupakan sebuah perangkat lunak bagi perdokumenan, pelaporan, dan penyampaian dalam bimbingan belajar yang disediakan untuk peserta didik dan pendidik. LMS sendiri dalam proses pembelajarannya menggunakan system computer, lunak, dan internet yang ditujukan untuk mengatur pembelajaran secara online, menyampaikan materi pembelajaran, memberikan laporan sebuah aktivitas, yang mana semua ini terhubung dan dapat diakses melalui internet. Selain itu, peserta didik dapat mengakses tugas, buku, dan materi. Mengapa digunakannya metode LMS dalam aplikasi Google Classroom hal ini dikarenakan LMS mempunyai banyak fitur sehingga dapat dikatakan memberi kemudahan para penggunanya seperti dalam dunia pembelajaran bagi pendidik dan peserta didik.

Supervisi pembelajaran terhadap peserta didik dapat dilakukan secara manual seperti: jika terdapat soal berupa essay maka nilainya dinilai dengan cara manual tidak otomatis. Adapun system dari Google Classroom seperti kirim email yang mana pendidik mengirimkan materi berupa tugas sedangkan peserta didiknya berusaha untuk menjawabnya. Akan tetapi yang berbeda ialah hanya pada tampilan berandanya saja. Dalam aplikasi Google Classroom pendidik dalam mensupervisi peserta didik dapat dilakukan dengan memberikan materi pembinaan dan bimbingan.

\section{REFERENSI}

Ellis, K. Ryann. (2009). A Field Guide to Learning Management System. American Society for Training and Development (ASTD)

Gredler, Margareth E. (2011). Learning and Instruction: Teori dan Aplikasi. Jakarta: Kencana.

Heinich, Robert, et al. (1999). Instructional Media and Technology for Learning. New Jersey: Prentice Hall.

Hardiyana, Andri. 2015. Implementasi Google Classroom sebagai Alternatif dalam Meningkatkan Mutu Pembelajaran di Sekolah. Karya Tulis Ilmiah, Cirebon: SMA Negeri 1 Losari.

Iftakhar, Shampa. (2016). Google Classroom: What Works and How? Journal of Education and Social Sciences, 3 (feb), 12-18.

Miarso, Y., (2004). Menyemai benih teknologi Pendidikan. Kencana.

Mungkasa, Oswar. (2020). Bekerja dari Rumah (Working from Home/WFH): Menuju Tatanan Baru Era Pandemi COVID 19. The Indonesian Journal of Development Planning, Vol IV No 2. 126-150 
Nawawi, H. Murni Martini. (1966). Penelitian Terapan (Yogyakarta Gajah Mada University Press,cet . 2.

Sadiman, Arief S., dkk. (1986). Seri Pustaka Teknologi Pendidikan No.6 Media Pendidikan. Pengertian, Pengembangan, dan Pemanfaatannya. Jakarta: CV Rajawali.

Sauri, S., Munawaroh, T., Riswanto, D., Nurbani, S. (2020). Pembelajaran Virtual pada Masa Pandemic Covid-19: Tantangan dan Solusi Permasalahan. Civics Education and Social Sciense Journal (CESSJ), Vol 2 No 2. 16-26

Sugiyono. (2006). Metode Penelitian Kuantitatif, Kualitatif dan R \& D. Bandung:Alfabeta.

Qomariyah, S., dan Nursobal, SL. (2019). Implementasi Pemanfaatan Google Classroom untuk Pembelajaran di Era Revolusi 4.0. SINDIMAS: Prosiding Seminar Nasional Hasil Inovasi Pengabdian Masyarakat. http:/ / dx.doi.org/10.30700/sm.v1i1.573

Yusuf, A. M. (2014). Kuantitatif, Kualitatif, \& Penelitian Gabungan. Jakarta: Kencana 